\title{
Near Peer Mentors to Address Socio-Emotional Issues Among Underrepresented Minority High School Students in Research Intensive STEM Programs: Perceptions of Students and Mentors
}

\author{
Kelli Qua', Otis Pinkard' ${ }^{2,3}$, Emma C. Kundracik', Diana Ramirez-Bergeron ${ }^{5,10}$, and Nathan A. Berger ${ }^{3,6,7,8,9}$ \\ ${ }^{1}$ Department of General Medical Sciences, ${ }^{2}$ Center for RNA Science and Therapeutics, ${ }^{3}$ Department of Genetics and Genome Sciences, ${ }^{4}$ Department of Molecular \\ Biology and Microbiology, ${ }^{5}$ Case Cardiovascular Research Institute, ${ }^{6}$ Department of Medicine, ${ }^{7}$ Department of Biochemistry, ${ }^{8}$ Case Comprehensive Cancer Center, \\ and ${ }^{9}$ Center for Science, Health and Society, Case Western Reserve University, Cleveland, Ohio, and ${ }^{10}$ Harrington Heart and Vascular Institute, University Hospitals, \\ Cleveland, Ohio
}

Keywords: Near Peer Mentors, Youth Enjoy Science, High School Students, Socio-Emotional Stress

Publication Date: May 14, 2020

DOI: https://doi.org/10.15695/jstem/v3i1.06

\begin{abstract}
A Near Peer Mentoring Program (NPMP) was developed in which Medical Student Training Program (MSTP) students met weekly with small groups of high school students who were participating in an intensive summer biomedical research immersion program. The goal of the NPMP was to provide and engage the high school students with opportunities to express and discuss their research and more importantly, their stresses and concerns. After initial reservations, the NPMP provided a comfortable venue for high school students to engage in discussions of both laboratory and personal topics. Overall, their concerns and stresses were expressed in five categories: 1) College Preparation, 2) Preparation for MD and PhD Training and Careers, 3) Summer Research Programmatic Issues and Laboratory Social Structure, 4) Social Issues, and 5) Health and Wellness. High school students identified the following major factors as contributing to programmatic success: relatability, role models, comfort and approachability, organization, and mentor fit. The Near Peer Mentoring initiative revealed the need for STEM and other programs targeting academic success and career development to be alert to social and emotional concerns of students and to provide opportunities for their expression, discussion and guidance.
\end{abstract}

\section{INTRODUCTION}

Engagement of secondary school students to participate in science, technology, engineering and mathematics (STEM) curricula and pursue related careers has become an important component of many education enrichment programs. The goals of such programs include preparing students for real-world STEM applications, providing career opportunities for personal success and maintaining capabilities and leadership in cutting edge technologies. Despite several prior initiatives, in 2010 the Federal government indicated a continued need to increase the STEM educational programs and provide the opportunities for underrepresented minorities (URM) (National Science Foundation, 2010). Existing programs at Case Western Reserve University School of Medicine (e.g., the Scientific Enrichment and Opportunity (SEO), and Youth Enjoy Science (YES) programs are currently focused on URM high school students (Qua et al., 2020). These programs emphasize the importance of increasing STEM careers and retention in minorities (Palmer et al., 2011).
While significant planning is devoted to creating engaging STEM curricula, various factors impacting student uptake and commitment to such programs (e.g., socioeconomic, emotional, environmental, and academic) are not always considered. High school students today report rates of depression and anxiety upwards of $25 \%$ in addition to tackling issues like drug abuse and cyberbullying (Bauman et al., 2013). An analysis of various data sources such as the Youth Risk Behavior Surveillance System reported increases between $12-33 \%$ in depressive symptoms, suicide-related outcomes, and suicide deaths among American adolescents between 2010-2015 compared to previous rates (Twenge et al., 2018). Academic stressors continue to increase with $26 \%$ of students expressing extreme distress over college application and admission processes (Shahmohammadi, 2011). Moreover, students in urban environment often face additional socioeconomic challenges which increase the impact of these factors.

As a result of recent concerns regarding the overall health 
and wellness of high school students participating in the SEO and YES summer biomedical research immersion programs at CWRU, we have developed a Near Peer Mentoring Program (NPMP). The benefits of mentorship for URM students have been reported for STEM pathways starting in college (e.g., Fuchs et al., 2016; Pfund et al., 2016; Robnett et al., 2019), but few studies have investigated the role of high-school and graduate student mentoring. In this program, MD/PhD students from the CWRU Medical Scientist Training Program (MSTP) were invited to serve as Near Peers Mentors (NPM). The MSTP students were assigned randomly and met weekly with small groups of high school students to address challenges they encounter. The following account describes the development and implementation of this program and the elucidation of some of the issues that the high school students identified as their concerns.

SEO and YES Program Descriptions. Case Western Reserve University (CWRU) is a leading research institution located in Cleveland, Ohio, a large Midwest city characterized by urban poverty and an academically challenged school system. The Case Comprehensive Cancer Center is a National Cancer Institute (NCI) designated comprehensive cancer center that coordinates cancer research activities at CWRU and its affiliated hospitals including the Cleveland Clinic and University Hospitals Cleveland Medical Center. The CWRU School of Medicine and the Case Comprehensive Cancer Center coordinate two highly integrated programs to excite, engage and immerse high school students in biomedical research, encourage their pursuit of careers in health related research and clinical care. The SEO program, supported mainly by philanthropy, has been in existence for 15 years. The SEO program enrolls 30 students per year and is focused on all aspects of biomedical research. There are no ethnic requirements for student participation in the SEO program. However, the students are preferentially selected from urban public schools, but also some from suburban and private schools. The Youth Engaged in Science (YES) program, now in its third year, is supported as an R25 training grant, by the National Cancer Institute; it enrolls 40 students per year, mostly URMs, and is focused on cancer research.

The SEO and YES programs, composed of a total of 70 high school students, are conducted as an integrated program that has recently been described (Qua et al., 2020). Applicants are required to be at least 14 years of age and to have a grade point average of 3.0 or higher. Elements of the application process that are considered in selection are a personal statement of career goals, interest(s) in science and cancer, and reasons for wanting to participate in the program. Applicants are also asked to provide their GPA, high school transcript, and two letters of recommendation (from their science teacher and guidance counselor). There is no prior laboratory experience required to apply, however, stu- dents returning for a second year of program participation have had previous experience. In our program, approximately $30 \%$ are returning students. Applications are reviewed and individually ranked by a group of high school guidance counselors and medical school faculty, who meet to determine the final list of students to be accepted.

After completing the application, selection, and enrollment process, students are oriented, trained in laboratory safety and immersed in individual research labs for an intensive 2-3 months experience. Students are provided with twice weekly scientifically focused Lunch and Learn seminars, practice SAT and ACT tests, counseled on college selection and the application process, as well as coached on scientific presentation style in preparation for a Capstone Poster Program where students present their research studies and results to an audience of students, faculty, family, mentors, and community leaders. Overall these programs are highly focused on STEM exposure, engagement, education and career orientation. However, little consideration is given to the socioemotional factors which may impact the students' ability to concentrate and fully benefit from these programs.

Developing the Near Peer Mentoring Program. In recent years, we initiated discussion sessions, in response to public concern about recreational drug use and also about suicide ideation among the Cleveland high school student population. Initially, the sessions were conducted by a faculty member addressing the entire student group. However, we quickly learned that students were reluctant to discuss these and similar issues with faculty and/or in large groups. Previous research on mentorship models pairing highschool and college/post-baccalaureate students support the use of a near peer mentorship model to encourage academic success (Jett et al., 2005; Loue, 2010; Tenenbaum et al., 2014; Tenenbaum et al., 2017). The Gains in the Education of Mathematics and Science program (GEMS) at the Walter Reed Army Institute of Research (WRAIR) described a successful near-peer model pairing high school students in laboratories with undergraduate and graduate students (Jett et al., 2005). The GEMS program reported the high-school and graduate student near-peer model allowed for an emphasis on scientific learning due to the expertise of graduate students and provided the opportunity for graduate students to develop teaching skills in the labs (Feldon et al., 2005). College or health profession school students have also been successfully utilized as mentors to provide social support for underrepresented minority high school students in the West Virginia Health Science and Technology Academy (McKendall et al., 2014). Based on these results and given our perceived need to provide closer mentorship to high school students, we subsequently arranged for students to meet in small groups with MSTP students to talk about these issues, 
and this approach led to open and robust discussions.

Recognizing the success of these engagements between the MSTP students with the YES and SEO high school students in our other programs, we initiated an open recruitment call via email and word of mouth to any interested MSTP student to attend regular weekly NPMP lunch meetings. Mentors were not offered any monetary compensation for their participation but were provided with lunches during meetings with high school students and/or with program leadership and during training meetings. Based on the number of requests received by program leadership, it is also clear that the MSTP students see their participation as sources for letters of recommendation for future positions such as internships and fellowships.

At an initial orientation meeting, faculty asked the MSTP students to encourage high school student interaction and discussion, and that they engage in constructive, confidential, and nonjudgmental dialogues. We suggested that the MSTP students encourage the high school students to select topics for discussion, but they also guide discussions to include recreational drug use, suicide ideation, mental health and pregnancy.

For weekly meetings, high school students were divided into seven groups of 10 students each. Distribution was arranged so that each group was as diverse as possible, based on gender, ethnicity, grade, school of origin, and scientific interest. Once each week, during the summer program, students and near peer mentors were provided with sack lunches and each group went off to convenient locations to eat and talk. After each small group encounter, the mentors participated in an one-hour debriefing session with the program staff to discuss the experience. Informal discussions were held with mentors to solicit their opinions and advice during these weekly debriefing program sessions.

\section{METHODS}

At the end of the summer, two volunteer focus groups were held with high school students and separate interviews were held with MSTP mentors to evaluate each of their reactions and recommendations for the NPMP. Additional data sources included notes from the weekly debriefing sessions with MSTP mentors, as well as a review of documents, such as field notes and anecdotal records obtained by the mentors, program staff and evaluators. Focus groups were facilitated by two trained moderators who are not directly involved with the program. Focus group sessions were recorded and transcribed (IRB20190229). Qualitative open coding for themes was conducted by a member of the research team. Each transcript was read line by line twice to identify a list of topics, sentiments, patterns presented by the data. This list was then reviewed with a second member of the research team and formalized into a set of codes with descriptions to be used for data analysis. First, open coding of all mentor data was conducted. This included a review of the mentor debriefing sessions, notes, documents and post-program informal interviews. Mentor data was focused on the weekly meetings and therefore had a strong focus on the topics discussed each week. The goal of this analysis was to identify the main topics discussed and the student and mentor insights on these categories. Secondly, the student focus groups were analyzed. The focus group guide probed for student experiences in general, but had a specific question about the NPMP experience and suggestions for improvement. All data were investigated for emerging themes and topics. After the initial coding of both student and mentor data, preliminary results were discussed with program leadership and MSTP mentors in order to validate and inform the findings.

\section{RESULTS}

MSTP Mentor Insights. Mentor insights were derived from the analysis of all mentor generated data: weekly debriefings, post-program informal interviews, and anecdotal records and notes. While high school students were initially cautious and reserved about speaking in these newly organized groups, they very quickly became comfortable and willing to engage in discussions of personal concern. During weekly NPMP meetings and at the end of the program, MSTP students were asked to report on the topics raised by the high school students. Topics were selected organically by the students, that is they were raised spontaneously in group discussions, then they were subsequently qualitatively grouped by the program evaluators into the following five categories; 1) College Preparation, 2) MD and PhD Preparation and Careers, 3) Program and Laboratory Structure, 4) Social Issues, and 5) Health and Wellness. Although, based on student interest, each group allocated different times to these five issues, mentors reported that college preparation, social issues, and health and wellness were the most discussed topics across groups.

College Preparation. High school student concerns about college preparation focused on characteristics of different college types, such as private versus public, size, location (i.e., urban, rural), and historically Black colleges and universities (HBCUs). Students were particularly interested in how to deal with the college application process, how to navigate the college admissions process, and how to identify and secure sources for support of college tuition. Mentors felt that this topic was the biggest driving stress factor for students with one mentor commenting, "College prep is such a major stressor for these students that it impacted their health and wellness, especially at SAT and college application time." The high amount of pressure placed on students was also mentioned by a mentor who stated, "The entire 
college application and preparation process creates stress between students and parents and the students really benefited from talking to others who were going through the same thing."

MD and PhD Preparation and Careers. The high school students took advantage of the MSTP near peers experience to raise questions regarding preparation and fulfilling requirements for $\mathrm{MD}, \mathrm{PhD}$, or MSTP programs. They also posed questions about career differences between an MD and a $\mathrm{PhD}$ versus the $\mathrm{MD} / \mathrm{PhD}$. High school students were concerned about the intensity of the first two years of medical school. They were particularly concerned about the long duration, in other words waiting so long to complete training, for careers in medicine and even longer for biomedical sciences. The most common concern was financial. High school students expressed concerns about funding this long duration of study, as well as the impact of this time during which they are not earning a salary.

Program and Laboratory Structure. Students had many questions about the SEO and YES programs. Coming from school systems where the goal is to demonstrate mastery of a subject by passing an exam, students were unsure of the expectations of the summer research program. They were particularly concerned about their own public speaking abilities and expectations for their capstone poster presentations. An interesting issue that students posed was how to answer questions when you do not know the answer. Students also noted they were often too nervous to ask questions. They did not feel confident or comfortable expressing when they did not understand a concept. This was evident in the laboratory and in the Lunch and Learn sessions.

Students were frank in their discussions on reasons why they were participating in the SEO and YES programs including self-interest, teacher pressure and parental pressure. Several students noted that their parents were "pushing" them to be competitive college applicants. Students inquired also about academic performance and its relation to further success. Students indicated that academic performance and college entrance were important causes of stress and sought strategies for dealing with stress. It is of note, that many of these students were only high school freshman and sophomores.

Students were also unsure of their expected interaction with laboratory mentors and the role of Principal Investigators (PI). Students were inquisitive of laboratory social dynamics - PI, post-doctorates, graduate students, high school students, research assistants, etc. Additionally, the students wanted advice on the laboratory environment. For most, this was their first experience in a research laboratory, working as part of a research team. Some students were uncomfortable with the laboratory hierarchy, reporting uncertainly on who to report to and ask questions. Students also noted the presence of high tech equipment and sought advice from their near peers.

Social Issues. Students expressed interest regarding a number of social issues. These included the social dynamics of high school, how these might differ in college and as noted above, the social dynamics in the research labs. Students were concerned about bullying, partying at school, pressure for drug and alcohol use, and how to resist. Students were inquisitive about career related work-life balance. Students were likewise interested in socioeconomic status, privilege and its influence on scientific career enhancement and success. One mentor noted the importance of social issues in science and described their mentorship experience as "an incredibly exciting and rewarding way to provide under-represented minority students the opportunity to see successful graduate students who were ethnicity, racially, and socioeconomically diverse."

Health and Wellness. In terms of health and wellness, students raised concerns about suicide and depression, sex education and birth control, violence in schools (fights among students, bomb threats, how to survive), mental health issues and where to get help. Issues were raised regarding social pressures, temptations and resistance strategies for drugs, tobacco products, vaping and alcohol use in high school. Concern was also expressed regarding sexual preference and how to deal with variations. One mentor noted on their experience: "During our weekly meetings I had students telling me about the everyday choices they had to make at school, like taking or turning down alcohol, marijuana, fights...there was a discussion about finding the right attitude to survive. These students are faced with these tough decisions every day and that was eye opening to me." In some cases, NPMs suggested students to meet with program leadership regarding concerns about substance abuse and sexual preference. These meetings were not mandatory and were targeted at finding help.

High School Student Focus Groups. Major themes that emerged from the high school student focus groups included: relatability, role models, comfort, organization and mentor fit. These themes are separate from the topics presented above and represent the students' opinions on the strengths and area for improvement in the NPMP. These themes were then presented and discussed with the MSTP mentors as a form of member checking. Three of these themes focused on the experiences of the high school students and illustrate the benefits of the Near Peer Mentoring. The latter two themes report ways Near Peer Mentoring can be adjusted to better meet the needs of the high schools. Themes are outlined in Table 1 with example quotations. 
Table 1. Summary of High School Student Focus Group Findings.

\section{Theme}

\section{Relatability}

Students identified more with mentors who could relate to their experience as a URM and/or urban high school student.

\section{Comfort}

Students believed the near peer setting was comfortable and they could approach their mentors with questions and problems.

Example Quotations

"...my mentor would talk about how [they] used to live in the inner city and there are things that happen and [the mentor] makes it positive and funny. So like, it was nice. Like we share our living situation, but like also we have a good laugh."

"[I loved] getting to talk with students that are in college every Wednesday who give us advice on how to go about solving an issue in our lab or even just in life in general that has been bothering us."

"[I] found it easier to talk to strangers in a way and we kind of bonded during the week."

"[I] thought [my mentor] was really approachable and I think did a good job of asking us what our feedback was and everything and was open."

"I loved Wednesdays because they allowed me to be free and open while I felt I was in a great environment."

\section{Role Model}

Students enjoyed learning about educational paths and future careers. Some students felt in school they were seen as "nerds", but identified positively the "science-loving" MSTP students.

\section{Organization}

Some mentor-mentee groups had more guided near-peer experiences than others.

\section{Mentor Fit}

Some students expressed lack of fit with their near peer mentor's personality and/ or communication style.
"It was just a lot of fun to meet [the MSTP students] and meet good kids who also are passionate about science and like working hard in school."

“...it was great meeting with some graduate students and they just tell you like how they got their experience and they were pretty candid about what it's like working [in research]."

"I would have a specific plan for the Wednesday lunch meetings. I think that it is a valuable opportunity to interact with medical students, but it needs to be more organized."

"I think that there should be more consistency throughout the groups, as some groups did more than others. Also, I think that the group leaders should be a bit more prepared with discussion questions or activities."

“The problem I had was with my Wednesday mentor... [they] weren't very outgoing and didn't seem to want to help me get through the struggle of doing something completely new which made me very frustrated for the first couple of weeks of the program."

"The mentor of my group was very immature in [their] structure of leadership. [They] allowed or sometimes even led the conversation to become extremely vulgar and even encouraged swearing and participated in swearing [themselves]..."

\section{DISCUSSION}

As indicated in the reported comments, the NPMP was an operational success in providing students with small group venues where they felt safe, comfortable and able to be free and open relating to each other and to a near peer who they recognized as group leader, but nonetheless, close enough to be non-threatening. From the comments, it appears that humor helps this relation, but stooping to vulgar language did not serve to engage students, emphasizing the importance that the mentor serves as a role model. Considering the role of personalities and communication styles as critical factors in mentoring (Bernier et al., 2005), it is clear that appropriate allowances should be made in the next iteration of this program. While the MSTP students were asked to encourage high school students to select topics and guide discussions, it is apparent from student evaluations that different MSTP students were more or less organized in their guidance and students responded differently to an unstructured format. In future plans for the NPMP, we will orient the MSTP students by providing them with comments derived from this year's program and recommend that they use this information to guide topic selection by high school students, while at the same time leaving the encounters open for students to propose topics (Table 2).

The lessons learned in the CWRU Near Peer Mentoring Program are summarized in Table 3 and discussed below. The NPMP served as an important indication that the high school students are significantly concerned and stressed about the entire process of transitioning to college and its impact on their future. At the same time, students clearly indicated that they were stressed by issues related to safety, social pressure, substance abuse and temptations, sexual preference and others. While our program is designed to immerse and excite students about STEM research activities, potentially influencing career commitments, it became clear, as a result of our NPMP, that social structure of the research laboratory was creating a new challenge for the students to understand and learn to navigate. Students' knowledge of hierarchies prior to their exposure to the laboratory setting is likely limited to families and schools, whose settings have a clear "leader" and a limited number of hierarchal ranks. For example, the concepts that the PI was the laboratory 
Table 2. Sample Engagement Activities and Guided Discussion Topics for Near-Peer Mentoring.

\section{ENGAGEMENT ACTIVITIES}

Eating lunch together as a group

Visiting the innovation lab on campus (3D printing, laser cutting, photography)

Visiting the medical student lounges

Eating a picnic outside

Story telling

Practicing poster presentation in front of the group

\section{DISCUSSION TOPICS}

Do you feel safe at your school? Is there violence or fighting?

If you couldn't do your dream career, what would you do instead?

What is the end goal of the research that you're conducting?

In what ways are you privileged? In what ways are you under-privileged?

Who in our society is responsible for teaching adolescents about sexual health and reproduction? The family, the school, doctors or nurses? What do you think about the way you were taught?

Do you have any childcare responsibilities? How does it affect your life?

How do you stay motivated to keep working hard when you're tired or frustrated?

Do you know anyone at school or in your family that uses drugs? How does it affect your relationship with them?

What motivates people to commit suicide? What does it mean to be mentally healthy or unhealthy?

leader sometimes caused uncertainty regarding who the student reported to especially when the PI was variably present due to other academic responsibilities. In subsequent years, we plan a more formal introduction to laboratory positions, which will include a discussion of their responsibilities and expectations for student interaction.

We are currently working with the Near Peer Mentoring team along with high school guidance counselors to coach the mentoring team members how to deal with some of the issues raised. In this upcoming year, we will hold a halfday orientation program with the NPMs to 1) review themes raised in this program, and 2) guide them in counseling and developing strategies with students by bringing in a high school student guidance counselor and a leading instructor for high school teacher training in counseling for academic success. These individuals will meet with the MSTP students on a regular basis to debrief and guide them after each of their near peer mentoring meetings.

High school students, in general, and especially those in programs targeted at achieving high academic success, are under significant psychological stress (Suldo and Shaunessy-Dedrick, 2013). The NPMP revealed, not surprisingly, but often overlooked, that the students in our program identified similar causes of social and biological stress, as those identified by other high school students, including academic pressure, career path issues and family stress (Suldo and Shaunessy-Dedrick, 2013; Acosta-Gomez et al., 2018). In addition, our students were further stressed by issues of personal safety, social structures, health and wellness. These issues have the potential to exacerbate acute anxiety and behavioral disorders in some students, while in others, they may lead to chronic stress and long-term cognitive, functional, and health problems (McClure and Pine, 2007). At a subtler level, these stresses may impact academic performance, career choice, and success. Thus, it is critical for organizers of targeted STEM programs to be alert to social and emotional behaviors of adolescents and to provide opportunities for their expression and guidance. Our experience indicates that

Table 3. CWRU Near Peer Mentoring Program: Lessons Learned.

\footnotetext{
1. High school students in intensive research oriented STEM programs are subject to multiple socio-emotional stresses which may impact their health, performance, career choice, and success. These may differ both qualitatively and quantitatively, depending on background.

2. Major areas of stress and concern among high school students in intensive research STEM preparation programs include a.) college preparation, b.) professional career training, c.) expectations of research immersion program, d.) social issues and laboratory social structure, e.) health and wellness.

3. High school students are reluctant to discuss their concerns in large groups and/or with faculty.

4. High school students are ready and eager to discuss these issues in small groups guided by Near Peer Mentors.

5. Near Peer Mentoring is an effective approach to engage high school students to identify and share their stresses, concerns, and coping strategies.

6. Characteristics of Near Peer Mentors that facilitate open dialogue include relatability, comfort, role models, organization and mentor fit.

7. Training Near Peer Mentors to guide high school students to develop effective coping strategies should improve their abilities to guide high school students to improve outcomes.
} 
Table 4. Near Peer Mentor Activities.

1. Pre-program Orientation Meeting - One half-day meeting to review previous experience, develop strategies, and orient NPMs to high school student guidance strategies.

2. NPM - High School Student Meetings - One-hour lunch meetings, one each week for eight weeks for NPM and high school students to examine psycho-emotional stressors.

3. NPM Debriefing Meetings - One-hour meeting, weekly times eight, immediately following NPM-High School Student meeting for an NPM to debrief and develop strategies with high school guidance counselor, counseling for success and program leadership.

4. Post-program Evaluation and Focus Session - One-hour review and focus session to consider lessons learned, follow-up and develop plans for following year.

the open, nonjudgmental structure of the NPMP encouraged students to identify and express these issues, to improve peer relationships and develop mutual support strategies.

Table 4 is an outline of the NPM activities scheduled for the coming year. It provides both an indication of the time commitment expected by the NPMs and an outline for their activities. The evaluation of this program will continue to conduct student focus groups and analysis of mentor discussions. The evaluation will be expanded to focus on quantifying the short term and intermediate effectiveness of the NPMP on students and mentors, including mentor training and mentor and mentee satisfaction. Anecdotally a few mentors commented on the value of this teaching experience saying that it increased their interest in teaching with one mentor specifically noting, "it really helped me realize the difference in thought processes and helped me think about how I teach those processes, like abstract writing." It is vital that the evaluation plan include a formal evaluation of increased teaching interest as well as investigate other possible rewarding aspects of this experience that could be used to promote this NPMP paradigm at other institutions. Future training sessions for faculty and mentors will also be provided and evaluated with a focus on guiding each other in describing effective, positive coping strategies. As noted above, we will also provide mentors with opportunities to interact with experienced, adolescent guidance counselors to help develop their own skills for counseling high school students and we will then evaluate the effectiveness of this new training and its impact on the NPMP program.

Overall, the Near Peer Mentoring Program provides both important opportunities for expression and discussion of socio-emotional stressors among high school students, as well as guidance experience for MSTP mentors who may be contemplating careers with teaching components.

\section{AUTHOR INFORMATION Corresponding Author}

Nathan A. Berger, MD, Case Comprehensive Cancer Center, Case Western Reserve University, 10900 Euclid Avenue, Cleveland, OH, 44106-4924. (216) 368-4084.nab@ case.edu

\section{Author Contributions}

The manuscript was written through contributions of all authors. All authors have given approval to the final version of the manuscript.

\section{FUNDING SOURCES}

Supported in part by NIH Grants P30CA043703, R25CA221718, and T32 GM007250.

\section{ABBREVIATIONS}

CWRU: Case Western Reserve University; GEMS: Gains in the Education of Mathematics and Science; HBCU: Historically Black Colleges and Universities; MSTP: Medical Student Training Program; NCI: National Cancer Institute; NPM: Near Peer Mentors; NPMP: Near Peer Mentoring Program; PI: Principal Investigator; SEO: Scientific Enrichment and Opportunity; STEM: Science, Technology, Engineering, and Mathematics; URM: Underrepresented Minorities; WRAIR: Walter Reed Army Institute of Research; YES: Youth Engaged in Science; YES: Youth Enjoy Science

\section{REFERENCES}

Acosta-Gómez, M. G., De la Roca-Chiapas, J. M., Zavala-Bervena, A., Cisneros, A. E. R., Pérez, V. R., Rodrigues, C. D. S., and Novack, K. (2018). Stress in high school students: A descriptive study. Journal of Cognitive Behavioral Therapy, 1(1), 1 .

Bauman S, Toomey RB, and Walker JL. (2013). Associations among bullying, cyberbullying, and suicide in high school students. Journal of Adolescence, 36(2), 341-50.

Bernier, A, Larose, S, and Soucy, N (2005). Academic mentoring in college: the interactive role of student's and mentor's interpersonal dispositions. Research in Higher Education, 46(1), 29-51.

Feldon, D. F., Peugh, J., Timmerman, B. E., Maher, M. A., Hurst, M., Strickland, D., ... and Stiegelmeyer, C. (2011). Graduate students' teaching experiences improve their methodological research skills. Science, 333(6045), 1037-1039. 
Fuchs, J., Kouyate, A., Kroboth, L., and McFarland, W. (2016). Growing the pipeline of diverse HIV investigators: the impact of mentored research experiences to engage underrepresented minority students. AIDS and Behavior, 20(2), 249-57.

Jett, M., Anderson, M.K., and Yourick, D. L. (2005). Near peer mentoring: A step-wise means of engaging young students in science. FASEB Journal, 19(5), A1396-A1396.

Loue, S. (2010). Mentoring health science professionals. Springer Publishing Company.

McClure, E.B., and Pine, D.S. (2007) Social Stress, Affects, and Neural Function in Adolescence in Adolescent Psychopathology and the Developing Brain, edited by D. Roner and E.F. Walker, Oxford University Press 2007;219-244.

McKendall S.B., Kasten, K., Hanks, S., and Chester, A. (2014). The Health Sciences and Technology Academy: An educational pipeline to address health care disparities in West Virginia. Academic Medicine, 89(1), 37-42.

National Science Foundation. Preparing the next generation of STEM innovators: Identifying and developing our Nation's human capital. (2010). Government Report. Arlington, VA.

Palmer, R.T., Maramba, D.C., and Dancy, T.E. (2011). A qualitative investigation of factors promoting the retention and persistence of students of color in STEM. The Journal of Negro Education, 1, 491-504.

Pfund, C., Byars-Winston, A., Branchaw, J., Hurtado, S., and Eagan, K. (2016). Defining attributes and metrics of effective research mentoring relationships. AIDS and Behavior, 20(2), 238-48.

Qua, K., Papp, K., Junk, D., Webb Hooper, M., and Berger, NA. (2020). Youth Enjoy Science Program at the Case Comprehensive Cancer Center: Increasing engagement and opportunity for underrepresented minority students, Ethnicity and Disease, 30(1), 15-24.

Robnett, R.D., Nelson, P.A., Zurbriggen, E.L., Crosby, F.J., and Chemers, M.M. (2019). The form and function of STEM research mentoring: A mixed-methods analysis focusing on ethnically diverse undergraduates and their mentors. Emerging Adulthood, 7(3), 180-93.

Shahmohammadi, N. (2011). Students' coping with stress at high school level particularly at 11 th and 12 th grade. Procedia-Social and Behavioral Sciences, 30, 395-401.

Suldo, S., and Shaunessy-Dedrick, E. (2013). The psychosocial functioning of high school students in academically rigorous programs. Psychology in the Schools, 50(8), 823-843.

Tenenbaum, L. S., Anderson, M. K., Jett, M., and Yourick, D. L. (2014). An innovative near-peer mentoring model for undergraduate and secondary students: STEM focus. Innovative Higher Education, 39(5), 375-385.
Tenenbaum, L.S., Anderson, M., Ramadorai, S.B., and Yourick, D. (2017). High school students' experience with near-peer mentorship and laboratory-based learning: In their own words. Journal of STEM Education, 18(3), 5-12.

Twenge, J.M., Joiner, T.E., Rogers, M.L., and Martin G.N. (2018). Increases in depressive symptoms, suicide-related outcomes, and suicide rates among U.S. adolescents after 2010 and links to increased new media screen time. Clinical Psychological Science, 6(1), 3-17. 